\title{
Energy Efficient Air Curtains for Industrial Gates in Cold Climates
}

\author{
Dr. A.S. Strongin, ${ }^{1}$ Dr. A.M. Zhivov, ${ }^{2 *}$ \\ ${ }^{1}$ Research Institute of Building Physics Russian Academy of Architecture and Construction Sciences NIISF RAASN, Moscow, \\ Russia \\ ${ }^{2}$ Engineer Research and Development Center Construction Engineering Research Laboratory, Champaign, Illinois, USA
}

\begin{abstract}
In geographical areas with cold climates, large, massively constructed industrial and warehouse buildings and logistics complexes are large consumers of energy resources. The great height and large contained volumes of the premises, the presence of a significant number of doors, and building configurations that include many transport corridors all require the use of air-thermal curtains to increase the energy efficiency of the buildings' heating, ventilating, and air-conditioning (HVAC) systems, which commonly produce several thousand kilowatts of thermal power. Optimization of air curtains can improve the microclimates of the premises, achieve savings in the initial construction costs, and also reduce energy consumption during operation by $10-20 \%$.
\end{abstract}

Keywords. Industrial buildings, logistics complexes, energy efficiency, cold climate, air curtains.

\section{Introduction}

Air curtains are local ventilation devices that are used in industrial buildings, warehouses, maintenance facilities to reduce leakage of airflow through gates/apertures in building enclosures. Their operation is based on damping effect of air jets that are supplied into the area of the open aperture. The advantages of air curtains include improvement of working conditions near open apertures, reduction of heat consumption and electric energy for heating the building and reduced loss of usable working space near gates due to ingress of cold air into the building [1]. Industrial buildings can have one or multiple gates equipped with different types of air curtains (Figures 1 and 2) [2,3]. Buildings in logistics complexes, as a rule, are comprised of modular unified sections that cover an area of up to $10,000 \mathrm{~m}^{2}$ each and that are equipped with gates for road and rail transport (Figure 2). A single complex can contain up to 50 or more sections. Building height is typically from 8 to $18 \mathrm{~m}$, and the specific heat load on the heating and ventilation systems in the design mode is from 3 to $10 \mathrm{~W} / \mathrm{m}^{3}$. Air curtains can affect the total heat load of the building from 20 to $60 \%$. [4].

\section{Establishing Targets}

In practice, there are various schemes that use air curtains (AC) and air-thermal curtains (ACT), including $\mathrm{AC}$ with partial or full use of unheated air [5-6].
Depending on the purpose and conditions, the following types of air curtains are usually applied:

- AC using indoor heated air (ACT),

- AC using indoor unheated air (IUAC).

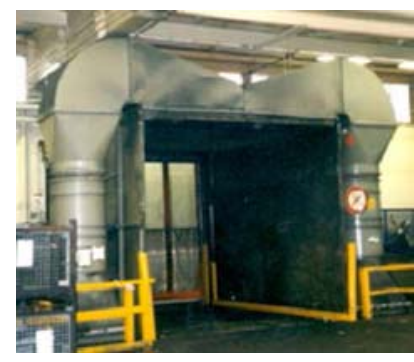

a

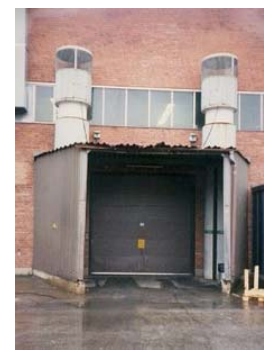

b
Figure 1. Protected aperure of industrial facilities : a machining shop of Ford Werke, Koeln-Neil, Germany; b Scania Cabin Plant in Oskarshamn, Sweden [3]

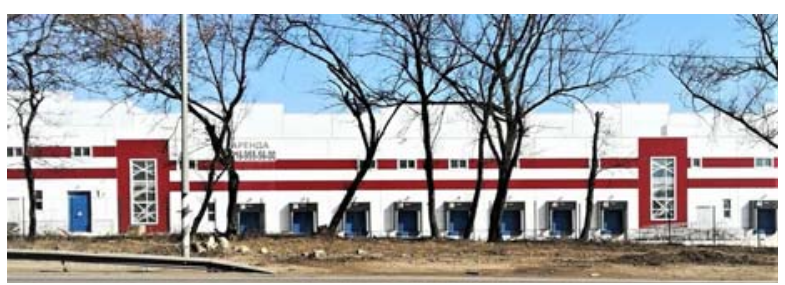

Figure 2. Multiple gates of a warehouse building. 
For ACT, it is recommended to use one- or twosided lateral or one-sided lower or upper supply with flat jets formed by a supply slot, or a system of nozzles placed at an angle to the door plane in the direction from which the air is supplied (Figure 3).

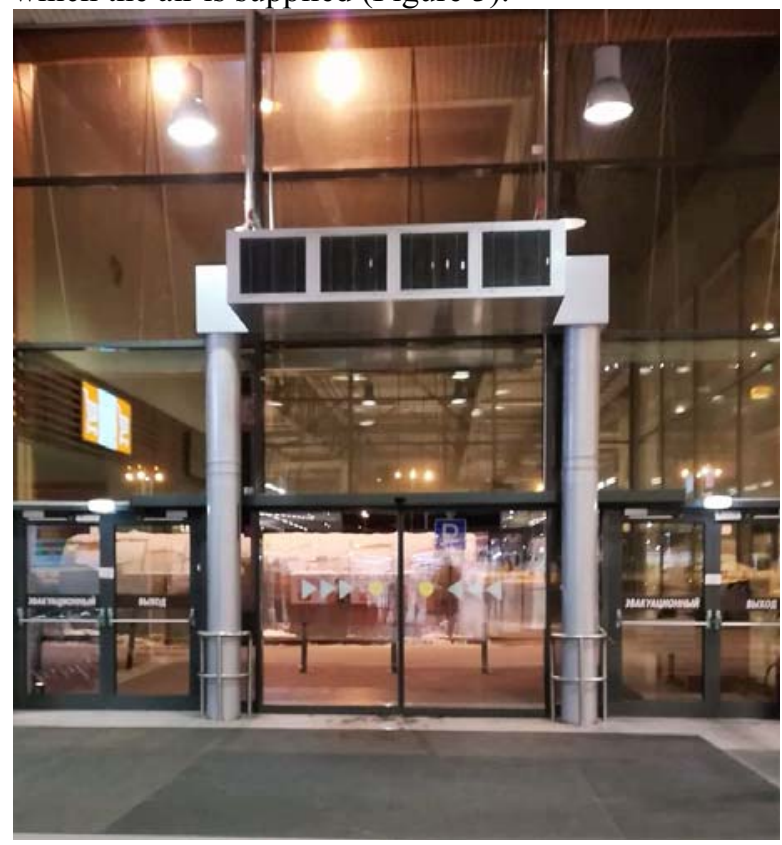

Figure 3. Air curtain using the indoor heated air (ACT design option).

For IUAC, as a rule, it is recommended to use a scheme that places the air supply at the bottom of the opening (Figure 4).

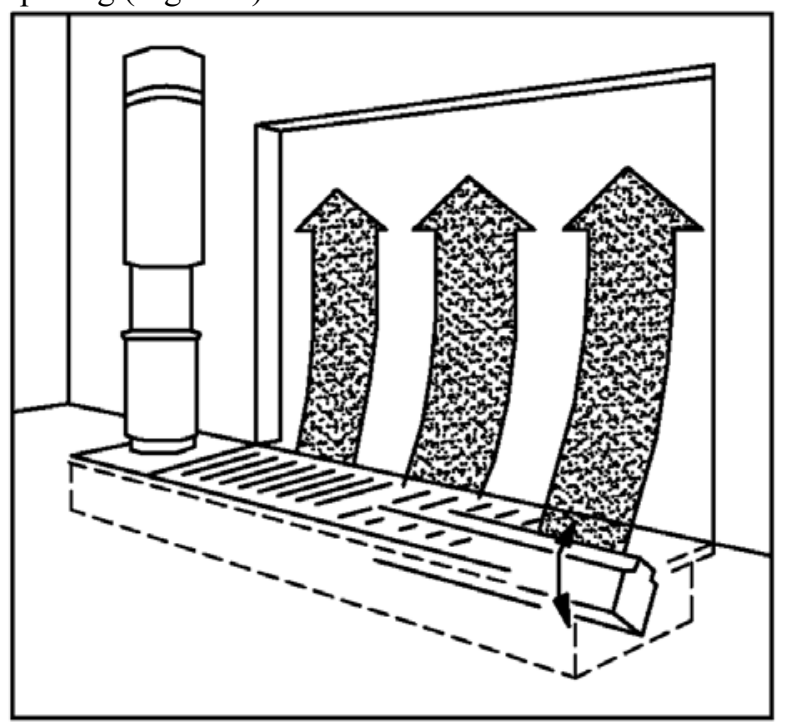

Figure 4. Air curtains using indoor unheated air (IUAC scheme).

It is recommended that IUAC be used to offset the normalized temperature of the air entering the opening without heating the air in the curtain in rooms:

- where the upper zone is overheated by more than $2{ }^{\circ} \mathrm{C}$ (if it is possible to use air from the upper overheated zone of the room);

- with excessive heat release (if technically possible and expedient);
- with a low rated air temperature in the working area near the gate or where there are no permanent workplaces near the gate.

IUAC have a more limited application than do ACT, but they do reduce the need to install air heaters in the air curtain units.

In addition to the types of air curtains considered above, in some cases, two-layer combined air-thermal curtains (CACT) and air curtains that circulate unheated outdoor air (OAC) can be used. CACT systems supply air through two flat jets, either parallel to each other or diverging at a slight (5-15 degree) angle (Figure 5).

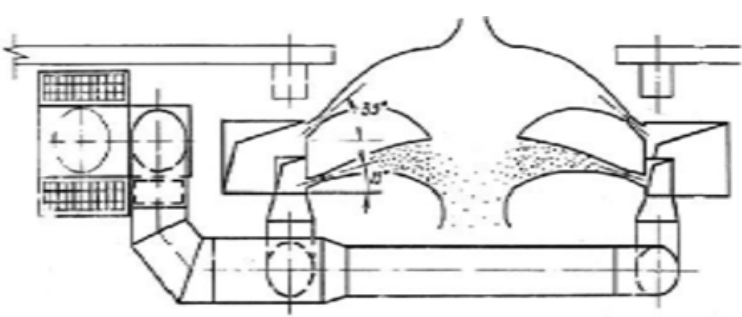

Figure 5. Schematic of horizontal cross-section of combined air heated thermal curtain (CACT design option).

Jets formed by nozzles in the duct located close to the door supply unheated room air. Jets supplied from nozzles in the duct located further from the door opening supply heated air (Figure 4). The heat loss resulting from the air curtain jet's contact with the outside air is reduced due to a decrease in its average temperature. To reduce the heat transfer between the external and indoor (more heated) jets of the CACT, it is recommended to leave a gap between them, which ensures the leakage of the internal air of the room into the space between the "outside" and "indoor" jets. The optimal size of this gap, the distance between the outlet nozzles, and the angles of air supply are determined when designing the CACT units.

The disadvantages of CACT are its relatively high cost and complex design, which limits the scope of its application.

The main advantages of $\mathrm{OAC}$ are that they are simple and cost effective; because they do not heat the supplied air, they incur no costs for thermal energy and associated equipment (heat exchangers, etc.) (Figure 6).

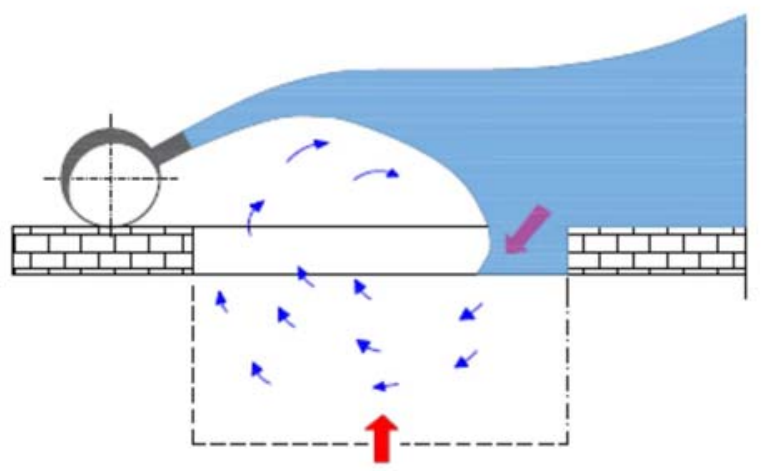

Figure 6. Schematic with horizontal crosse-section of air curtain using the outside unheated air (OAC scheme). 
At the same time, OAC have a number of disadvantages that limit the scope of their application:

- Occupants' discomfort due to high air velocity in the vicinity of the jet when workplace is located close to the gate or people have to walk/drive through the jet.

- $\mathrm{OAC}$ is unsuitable for use in rooms with moisture release due to the potential for fogging.

Depending on the design of the OAC, air circulation is created in one of two areas of the room, either closed (restricted to the area of the gate) or open to the volume of the room. Closed circulation is preferable if the purpose is to thermally protect the opening; open circulation will allow heat exchange between the air of the room and the air of the circulation zone due to the absence of a directed averaged airflow and the mechanism of turbulent exchange.

For all types of premises that use artificial cooling (refrigerating chambers, air-conditioned warehouses, etc.), the ACC curtain design is used. ACC helps to reduce the load placed on the refrigeration equipment, reduces energy costs, and increases the equipment service interval. ACC also reduces the potential for emergency situations associated with the formation of condensate and ice. As a rule, ACC units are placed above the gate (top supply), outside the cooled room. Air supply is directed at a slight angle to the plane of the door opening. Figure 7 shows the airflow during ACC operation.

The selection of the optimal air curtain scheme can be a difficult task that requires technical and economic calculations.

Unfortunately, the parametric range of curtain units offered on the market is not optimal, especially for road and railway gates. As a rule, the established design practice is guided by manufacturers' recommendations, which do not always provide complete and reliable information. Consequently, the consumer may receive an energy-inefficient unit that does not properly protect the opening.

To eliminate the risk of making an uninformed or subjective decision, it is necessary to develop reasonable criteria for choosing energy efficient AC solutions.

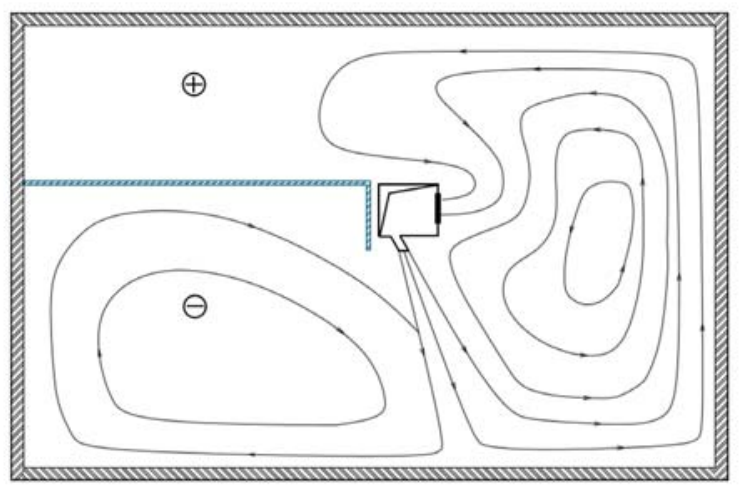

Figure 7. Schematic of vertical cross-section showing airflow during ACC operation according to [7].

\section{Methodology}

To compare various design and circuit solutions of $\mathrm{AC}$ and $\mathrm{ACT}$, it is proposed to apply the following dimensionless indicators/efficiency criteria.

The criterion for the dynamic efficiency of $\mathrm{AC}$ is given by:

$$
E=\frac{\Delta p H B}{2 I_{0}}
$$

where

$\Delta \mathrm{p}=$ the calculated pressure drop in the gate area, $\mathrm{Pa}$;

$I_{0}=$ initial impulse of the air jet, $\mathrm{N}$;

$H, B=$ dimensions of the gate opening, $\mathrm{m}$.

Criterion $E$ shows how effectively the initial impulse of the jet is used when sliding the opening, i.e., what fraction of the initial impulse goes into backpressure.

The energy efficiency criterion of $\mathrm{AC}$ is given by:

where

$$
\eta=1-q_{a c} / q_{0}
$$

$q_{a c}, q_{0}=$ heat losses through the opening, respectively, protected and not protected by the air curtain, in $\mathrm{kW}$. The thermal power of ACT is taken into account in the amount of heat loss.

$\eta=\eta=1$ indicates an ideal air curtain (that completely eliminates heat loss in the opening), and $\eta=0$ means no air curtain (unprotected opening).

Note that, for a poorly arranged AC, this criterion can be negative due to the intensification of heat transfer in the opening or excessive use of thermal power.

The criterion for the temperature (hygienic) efficiency of the air curtain is given by:

$$
\theta=1 \text { - (ti-tm) / (ti-to) }
$$

where

$t_{i}, t_{o}, t_{m}=$ the temperature of the indoor, outdoor, and mixed air, respectively, entering the room, in ${ }^{\circ} \mathrm{C}$. The air temperature $t_{m}$ is normalized by hygienic requirements, consideration of locations of permanent job places, and the nature of production conditions.

$\theta=\theta=1$ means ideal air curtain $\left(t_{m=} t_{i},\right), \theta=$ 0 - absence of air curtain. This criterion is convenient to use when making control measurements and setting up equipment.

When doing these calculations, it is advisable to use the following dependencies drawn from the law of conservation of momentum in a selected circuit, and from the heat transfer of turbulent jets.

The initial air jet speed can be calculated by the formula:

where

$$
\mathrm{V}_{0}=\left[\Delta \mathrm{P} \mathrm{HB} / 2 \beta_{0} \rho \mathrm{As} \mathrm{E}\right]^{0,5}, \mathrm{~m} / \mathrm{s}
$$

$$
\begin{aligned}
\beta_{0}= & \text { the Boussinesq coefficient } \\
\rho= & \text { the density of the air supplied, } \mathrm{kg} / \mathrm{m}^{3} \\
A_{S}= & \text { the total area of air outlet openings of } \\
& \text { the air curtain, } \mathrm{m}^{2} .
\end{aligned}
$$

The temperature of the air mixture, $t_{\mathrm{m}}$, entering the room can be calculated using the formula:

$$
\mathrm{t}_{\mathrm{m}}=\mathrm{t}_{\text {in }}-(1-\mathrm{m} 1-\mathrm{m} 2) \text { to }-\mathrm{m} 2 \mathrm{t}_{\text {in }} / \mathrm{m} 1,{ }^{\circ} \mathrm{C}
$$


where $m 1, \mathrm{~m} 2$ are dimensionless coefficients obtained by calculating the heat transfer of turbulent jets.

\section{Results}

Table 1 lists initial data and Table 2 lists the results of calculations done to compare different types of air curtains applied under the same conditions (i.e., door size, climate, building type, opening mode, etc.). Selected air curtains were similar in design. Calculations were done using formulas (4) and (5) and the methods given in [8-9]. Efficiency criteria were calculated using formulas (1), (2), and (3).

Table 1. Initial data for calculations (high-bay warehouse)

\begin{tabular}{|c|c|c|c|c|c|c|c|c|}
\hline \multirow[b]{3}{*}{$\begin{array}{c}\text { Gate } \\
\text { size, } m\end{array}$} & \multicolumn{4}{|c|}{ Design Conditions } & \multicolumn{4}{|c|}{ Operating Conditions } \\
\hline & \multicolumn{2}{|c|}{ Nominal } & \multicolumn{2}{|c|}{$\begin{array}{c}\text { Average } \\
\text { Heating } \\
\text { Period }\end{array}$} & \multirow[b]{2}{*}{$\begin{array}{l}\mathbf{t}_{\text {in }}, \\
{ }^{\circ} \mathrm{C}\end{array}$} & \multirow[b]{2}{*}{$\begin{array}{c}\text { Days - will } \\
\text { continue } \\
\text { heating } \\
\text { period }\end{array}$} & \multicolumn{2}{|c|}{ Gate Opening Mode } \\
\hline & \begin{tabular}{|l}
$\mathbf{t}_{\mathbf{0}}$, \\
${ }^{\circ} \mathbf{C}$ \\
\end{tabular} & $\begin{array}{c}\Delta \mathbf{p}, \\
\mathbf{P a}\end{array}$ & $\begin{array}{c}\mathbf{t}_{\mathbf{0}},, \\
{ }^{\circ} \mathrm{C}\end{array}$ & $\begin{array}{c}\Delta \mathbf{p}, \\
\mathbf{P a}\end{array}$ & & & $\begin{array}{c}\text { Number of } \\
\text { Openings } \\
\text { per day }\end{array}$ & $\begin{array}{c}\text { Duration } \\
\text { of One } \\
\text { Opening } \\
, \mathrm{s}\end{array}$ \\
\hline $3.6 * 3.6$ & -30 & 5.83 & -5 & 2.33 & 20 & 250 & 20 & 240 \\
\hline
\end{tabular}

Table 2. Results of comparative calculations.

\begin{tabular}{|c|c|c|c|c|c|c|c|}
\hline \multirow[b]{2}{*}{$\begin{array}{c}\text { Air curtain } \\
\text { type }\end{array}$} & \multicolumn{3}{|c|}{ Design parameters } & \multicolumn{4}{|c|}{ Efficiency } \\
\hline & $\begin{array}{c}\text { Initial } \\
\text { jet } \\
\text { velocity, } \\
\text { m / s } \\
\end{array}$ & $\begin{array}{l}\text { Temperature } \\
\text { of the air } \\
\text { mixture } \\
\text { entering the } \\
\text { room, }{ }^{\circ} \mathrm{C}\end{array}$ & $\begin{array}{c}\text { Heat loss } \\
\text { through } \\
\text { the door } \\
\text { opening in } \\
\text { the design } \\
\text { mode, qac, } \\
\text { kW } \\
\end{array}$ & $\eta$ & $\theta$ & $\begin{array}{c}\text { annual } \\
\text { heat loss } \\
\text { through } \\
\text { the } \\
\text { opening, } \\
\mathrm{kW} \cdot \mathrm{h} / \\
\text { year } \\
\end{array}$ & $\begin{array}{c}\text { annual } \\
\text { savings } \\
\text { heat, } \\
\mathbf{k W} \cdot \mathbf{h} / \\
\text { year }\end{array}$ \\
\hline $\begin{array}{c}\text { AC- absent } \\
\text { (unprotected } \\
\text { opening) }\end{array}$ & 0 & -30 & 546 & 0 & 0 & 60000 & 0 \\
\hline ACT & 15.4 & 20 & 282 & 0.49 & \begin{tabular}{|l|}
1.0 \\
\end{tabular} & 30000 & 30000 \\
\hline IUAC & 28 & 11 & 136 & 0.75 & 0.82 & 13700 & 46300 \\
\hline $\mathrm{OAC}$ & 14.5 & -18 & 82 & 0.85 & 0.24 & 9900 & 50100 \\
\hline CACT & 15 & 20 & 140 & 0.74 & 1.0 & 15800 & 44200 \\
\hline
\end{tabular}

Results show that the traditional ACT with heated air saves about half the heat loss through the door opening (compared to the unprotected opening) and provides an optimum temperature mix equal to the room air temperature:

$$
t_{\mathrm{m}}=t_{\text {in }}=20^{\circ} \mathrm{C} ; \theta=1 ; \mathrm{E}=0.28 ; \eta=0.49 \text {. }
$$

IUAC saves about 1.5 more heat energy compared to ACT, but with a lower hygienic (temperature) efficiency:

$$
t_{\mathrm{m}}=1{ }^{\circ} \mathrm{C} ; \theta=0.82 ; \mathrm{E}=0.28 ; \eta=0.75 \text {. }
$$

$\mathrm{OAC}$ provides the best energy savings, but the worst results in terms of hygienic efficiency. OAC saves $67 \%$ more heat energy than the traditional ACT and 28\% more than the IUAC. At the same time, a low temperature zone forms near the open doorway:

$$
t_{\mathrm{m}}=-18^{\circ} \mathrm{C} ; \theta=0.24 ; \mathrm{E}=0.36 ; \eta=0.85 \text {. }
$$

In terms of energy efficiency, CACT is comparable to IUAC, and in terms of hygienic (temperature) efficiency, is comparable to traditional ACT:

$$
t_{\mathrm{m}}=t_{\text {in }}=20^{\circ} \mathrm{C} ; \theta=1 ; \mathrm{E}=0.2 ; \eta=0.74 \text {. }
$$

\section{Conclusions}

1.Unprotected open doorways/apertures of industrial and logistics complexes buildings result in uncomfortable working conditions in these buildings and in significant heat losses and reduction of usable working area near gates, especially in buildings located in cold climate. Air curtains are local ventilation devices that are used to reduce air leakage through the open apertures. This paper describes the air curtain evaluation methodology, that can be used to determine application for various types of air curtains.

2. Traditional air curtains that utilize only heated indoor air (ACT) can be used for small, rarely opened doors in mild climates.

3. Air curtains supplying unheated internal air (IUAC) provide and optimal combination of lower energy consumption, better indoor environment, and installed cost. As a rule, its use is limited by the complexity of its construction, which involves installation of underground channel.

4. Air curtain supplying unheated outside air (OAC) has the best heat-shielding properties, the lowest cost, but creates the worst indoor air environment. It can be used in buildings with low thermal environmental requirements from occupants and production processes located in the gate vicinity.

5. Use of double combined air-thermal curtains (CACT) is recommended for buildings with stringent requirements to the working area microclimate located in severe climatic conditions.

6. To evaluate and compare the effectiveness of various air and air-thermal curtains for application at industrial and warehouse building apertures, it is recommended to use the following indicators:

- Dynamic efficiency E

- Energy efficiency $\eta$

- Thermal environmental (hygienic) efficiency $\theta$.

Finally, the most optimal solution will also consider Life-Cycle Cost efficiency.

\section{References}

[1] A. M. Zhivov, E. O. Shilkrot, and A. S. Strongin, "Industrial ventilation," Design Guide Book, ch. 7, Academic Press, 2001.

[2] A. Strongin. 2000. Chapter 7. Industrial Ventilation Design Guidebook. Editors: H. Goodfellow and E. Tahti. Academic Press.

[3] Ventilation Guide for Automotive Industry. 2000. Editor: Alexander Zhivov. HPAC Engineering.

[4] A. S. Strongin, "Assessment of Efficiency of Hot Air Curtains for Gates of Process and Warehouse Buildings," ABOK, no. 3, p. 24-29, 2020.

[5] A. S. Strongin, "Aerodynamic protection of hangars against cold ingress through apertures," Building Services Engineering Research and Technology. CIBSE, Series A, vol. 14, no. 1, 1993.

[6] A.S. Strongin, "Reduction of the energy consumption in air curtains", in A.S. Strongin and 
M.V. Nikulin, Proceedings of the Cold Climate HVAC'94 Conference, Rovaniemi, Finland, 1994.

[7] G. Verhaeghe, "Study of air curtains used to restrict infiltration into refrigerated rooms," in G. Verhaeghe, M. V. Belleghem, A. Willockx, I. Verhaert, and M. D. Paepe, Heat Transfer. Fluid Mechanics and Thermodynamics, Proceedings of the 7th International Conference, pp. 1763-1769, 2010.

[8] A. M. Zhivov, E. O. Shilkrot, and A. S. Strongin, "HVAC application," ASHRAE Handbook, Ch. 2829, 1999.

[9] A. M. Grimitlin, "Air curtains for buildings and technological installations," in A. M. Grimitlin and A. S. Strongin, Doe, St. Petersburg, 2018. 